\title{
UNA REVISIÓN SOBRE LAS VARIANTES HISTÓNICAS Y LA REGULACIÓN DE LA EXPRESIÓN GÉNICA
}

\section{A REVIEW ON HISTONE VARIANTS AND THE REGULATION OF GENE EXPRESSION}

\author{
Darío Arízala-Quinto ${ }^{1,2}$ \& Fabio Idrovo-Espín ${ }^{1,3}$
}

Recibido: 13 de septiembre 2019 / Aceptado: 3 de diciembre 2019

DOI: 10.26807/ia.v8i1.116

Palabras clave: Epigenética, histona canónica, expresión génica.

Keywords: Epigenetics, canonic histone, gene expression.

\section{RESUMEN}

El nucleosoma es una estructura formada por un octámero de histonas $\mathrm{H} 2 \mathrm{~A}$, $\mathrm{H} 2 \mathrm{~B}, \mathrm{H} 3$ y $\mathrm{H} 4$ alrededor del cual se enrolla el ADN, en algunos casos pueden presentarse variantes histónicas que cambian dramáticamente las propiedades del nucleosoma, así como también su interacción con el ADN. Estas variantes, que ocurren de forma natural en los organismos, forman parte de la epigenética,

1 Universidad de Las Américas, Facultad de Ingeniería y Ciencias Aplicadas, Ingeniería en Biotecnología,

Quito Ecuador.

2 University of Hawaii at Manoa, College of Tropical Agriculture and Human Resources, Department of

Plant and Environmental Protection Sciences, Honolulu United States of America (arizala@hawaii.edu) 3 Universidad Central del Ecuador, Facultad de Ciencias Químicas, Quito Ecuador (fmidrovo@uce.edu.ec) 
la misma que se refiere al estudio de la regulación de la expresión génica sin la alteración de las secuencias genómicas de los mismos. Esta revisión identifica algunos aspectos sobre las variantes histónicas y su forma singular de regular la expresión génica, temas que actualmente son motivo de numerosas investigaciones alrededor del mundo.

\section{ABSTRACT}

Nucleosome is a structure formed by an octamer of $\mathrm{H} 2 \mathrm{~A}, \mathrm{H} 2 \mathrm{~B}, \mathrm{H} 3$ and $\mathrm{H} 4$ histones around which the DNA is rolled, in some cases histone variants that dramatically change the properties of the nucleosome, as well as its interaction with DNA may, occur. These histone variants, which occur naturally in organisms, are part of epigenetics, which refers to the study of the regulation of gene expression without the alteration of the genomic sequences of the organisms. This review identifies some aspects of historical variants and the unique way in which gene expression is regulated, issues that are currently the subject of numerous research around the world. 


\section{INTRODUCCIÓN}

El ADN eucarionte está organizado en una estructura altamente regulada denominada cromatina, con la finalidad de mantener la estabilidad e integridad del genoma. La cromatina está formada por una repetición de nucleosomas. Este último es un complejo proteico en el cual se enrolla el ADN. Canónicamente, el nucleosoma es un octámero compuesto por pares de histonas $\mathrm{H} 3, \mathrm{H} 4, \mathrm{H} 2 \mathrm{~A}$ y H2B (Luger et al., 1997), mientras que las histonas $\mathrm{H} 1$ se unen en los sitios de entrada y salida del ADN en el nucleosoma (Hergeth \& Schneider, 2015).

Hace 77 años se acuñó el término "epigenética" (Waddington, 1942), para describir la interacción entre el ambiente y los genes que conducen al desarrollo de un fenotipo determinado. Actualmente la epigenética se entiende como los cambios en la dinámica, flexibilidad y arquitectura de la cromatina que no alteran o mutan la secuencia del ADN (Cedar \& Bergman, 2011; Lauria \& Rossi, 2011). Estos cambios (colectivamente conocidos como modificaciones epigené- ticas) modulan la expresión del genoma, son estables y se heredan durante los procesos de división celular mitótica o meiótica (Springer \& Kaeppler, 2008; Tammen et al., 2013; Tarakhovsky, 2010). Las modificaciones epigenéticas permiten al núcleo adaptarse, responder y realizar funciones vitales para las células ante diferentes condiciones y estímulos ambientales (Adalsteinsson \& Ferguson-Smith, 2014: Shaytan et al., 2015).

En síntesis, la epigenética radica en el control de la expresión génica y describe los cambios heredables en la función del genoma sin que existan cambios en la secuencia de nucleótidos de ADN.

Existen algunas formas de modificación epigenética que sorprenden por su versatilidad y elegancia (Margueron \& Reinberg, 2010; Tammen et al., 2013; Tost, 2009), entre ellas, y motivo de esta revisión, se encuentran las referidas variantes histónicas que conllevan a una composición de histonas diferente. 


\section{MATERIALES Y MÉTODOS}

De forma general, para determinar la estructura de los nucleosomas y las histonas que lo conforman, se realiza difracción de rayos $\mathrm{X}$ de extractos purificados de histonas y nucleosomas (Kujirai et al., 2016; Tachiwana et al., 2011: Luger et al., 1997). Para estudiar la interacción de las histonas y el ADN se utiliza la técnica de Inmunopurificación de cromatina, tal como se describió en los experimentos realizados por Kumar \& Wigge (2010) en células vegetales. En este mismo trabajo se evaluó la expresión de genes regulados por las variantes histónicas por PCR cuantitativa (qRTPCR). La abundancia de transcritos evaluada por Duan et al., (2019) se realizó mediante secuenciación de RNA (RNA-Seq) y qRT-PCR verificada. Estos procedimientos son los más usuales en estudios de este tipo.

\section{RESULTADOS}

\section{Histonas canónicas y variantes}

A nivel del nucleosoma, las histonas canónicas que organizan y empaquetan el ADN dentro del núcleo pueden ser intercambiadas por variantes his- tónicas, también conocidas como histonas de reemplazo, presentes en casi todos los eucariontes (Figura 1) (Cheema \& Ausió, 2015, Talbert \& Henikoff, 2010).

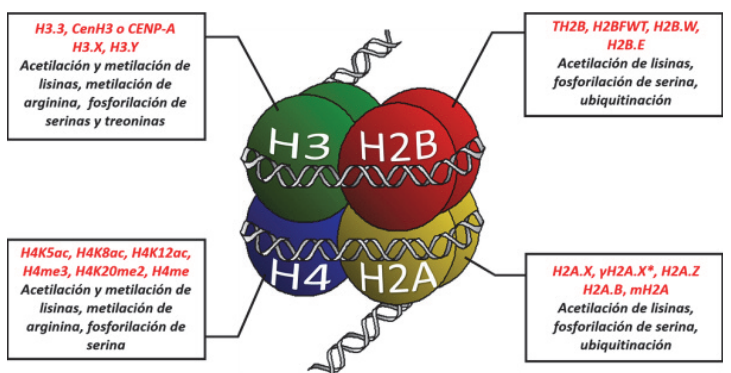

Figural. Octámero de histonas canónicas, en cada recuadro se señalan algunas variantes posibles (rojo) y las formas comunes de modificación de estas histonas (negro), el (*) denota modificación post traduccional de la variante H2A.X. 
La divergencia en la estructura primaria de las variantes histónicas conlleva a únicas y particulares modificaciones post traduccionales que no se observan en las histonas comunes (Szenker et al., 2014).

A nivel bioquímico, las variantes histónicas presentan cambios en las secuencias de aminoácidos con relación a sus contrapartes (Weber \& Henikoff, 2014), pudiendo variar su secuencia en solo cuatro a cinco aminoácidos como ocurre con la histona H3.3 o, por el contrario, pueden incorporar macro dominios o largos polipéptidos en sus extremos C-terminal como las variantes macroH2A y $\mathrm{H} 2 \mathrm{~A} . \mathrm{Z}$, respectivamente; incluso pueden presentar truncamiento en su extremo carbonilo como, por ejemplo, la histona H2A.B que carece de 19 aa en el extremo C-terminal, que sí están presentes en la histona canónica (Santoro \& Dulac, 2015; Szenker et al., 2014; Zink \& Hake, 2016).

Estas diferencias que muestran las histonas de reemplazo respecto a las proteínas comunes afectan la configuración, estabilidad, estructura y dinámica de los nucleosomas y, en general, producen efectos significati- vos a nivel del genoma (Weber \& Henikoff, 2014). Así, por ejemplo, los nucleosomas que contienen la variante $\mathrm{H} 2 \mathrm{~A} . \mathrm{B}$ o la variante $\mathrm{CenH} 3$ compactan unos 30 pares de bases pb menos, en contraste con las 147 pb del nucleosoma común (Talbert \& Henikoff, 2010). Estos eventos alteran la longitud de la hélice de ADN que se enrolla sobre el núcleo de histonas, la estabilidad propia del nucleosoma y la estructura secundaria de la cromatina (Szenker et al., 2014). De hecho, los nucleosomas que presentan la variante $\mathrm{H} 2 \mathrm{~B}$ inhiben el plegamiento y disminuyen el grado de compactación de la cromatina (Talbert \& Henikoff, 2010); mientras que, en algunos casos, los nucleosomas que incorporan la variante CenH3 enrollan el ADN en un giro orientado hacia la derecha, en comparación con el típico giro hacia la izquierda observado en el nucleosoma convencional (Cheema \& Ausió, 2015: Talbert \& Henikoff, 2010).

La combinación de las histonas de reemplazo dentro del nucleosoma juega un papel vital en la estabilidad de los nucleosomas (Szenker et al., 2014). Los nucleosomas que incor- 
poran dos formas de una variante de histonas (nucleosomas homotípicos) son mucho más estables in vivo que los nucleosomas heterotípicos (aqueIlos que contienen solo una forma de la variante de histona); este hecho se puede ejemplificar con el nucleosoma H2A.Z-H2A.Z, el cual presenta un mayor grado de compactación y mejora la elongación de la transcripción respecto al nucleosoma homotípico (H2A-H2A.Z), que tiende a desestabilizar el octámero de histonas (Cheema \& Ausió, 2015; Santoro \& Dulac, 2015).

La interacción de las histonas de unión $(\mathrm{H} 1)$ con el nucleosoma y el ADN también son afectados por la presencia de las histonas de reemplazo (Bönisch \& Hake, 2012; Szenker et al., 2014). Los estudios realizados respecto a este punto muestran que las variantes $\mathrm{H} 2 \mathrm{~A} . \mathrm{Z}, \mathrm{H} 2 \mathrm{~A}$.B, macroH2A y H3.3 evitan la unión de la histona H1 sobre los nucleosomas (Cheema \& Ausió, 2015; Szenker et al., 2014). Esta característica puede, de cierta manera, favorecer el estado transcripcional de genes funcionales (Cheema \& Ausió, 2015).
Las moléculas encargadas de garantizar la incorporación, el reemplazo e intercambio de las variantes histónicas en los respectivos nucleosomas son las chaperonas de histonas y los complejos remodeladores de la cromatina (Ray-Gallet \& Almouzni, 2010; Vardabasso et al., 2014; Zink \& Hake, 2016).

\section{Genes que codifican para variantes histónicas}

Se ha observado que la expresión de genes que codifican para las variantes histónicas se realiza por genes únicos o por genes huérfanos, definidos como genes que poseen regiones codificantes de proteínas pero que no tienen homólogos reconocibles en especies distantemente relacionadas (Skene \& Henikoff, 2013; Shaytan et al., 2015). Estos genes forman transcritos primarios con exones e intrones (Figura 2a) los cuales, luego del splicing, presentan en su extremo 3' una cola poli-A (Szenker et al, 2014). 
a)

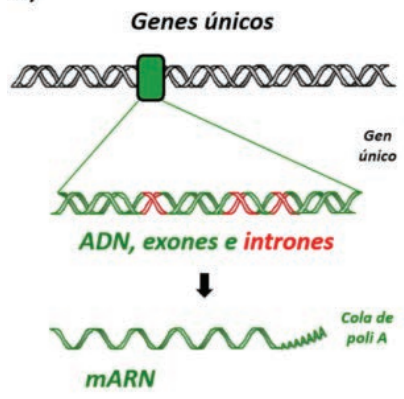

b)

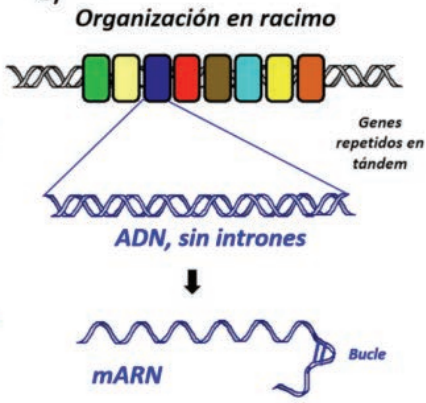

Figura 2. Características diferenciales de genes que codifican para histonas: a) genes codificantes de las variantes histónicas b) genes codificantes de histonas canónicas, alta expresión durante la fase S, Basado en Szenker et al., 2014

En cambio, en los genes de histonas canónicas, son codificados por un conjunto organizado en varias copias de genes que dan lugar a transcritos desprovistos de intrones y con un extremo 3' (Figura 2b) que, en vez de una cola poli-A, contienen una secuencia de 26 pares de bases (pb), la cual forma un bucle de horquilla (Skene \& Henikoff, 2013; Szenker et al., 2014).

Las variantes histónicas presentan un amplio repertorio de localización, abarcando todos los dominios de cromatina (eucromatina y heterocromantina) y varias regiones del genoma (genes activos, genes reprimidos, genes silenciados, elementos regulatorios, etc.) (Cheema \& Ausió, 2015; Santoro \& Dulac, 2015). Adicionalmente, se ha observado que la mayoría de genes asociados con variantes histónicas, se expresan constitutivamente durante todo el ciclo celular y su incorporación en el nucleosoma es independiente de la replicación. En contraste, en los genes que codifican para histonas canónicas (replicativas), la expresión está ligada a la fase $S$ del ciclo celular y su incorporación en la cromatina es dependiente de la replicación (Skene \& Henikoff, 2013; Cheema \& Ausió, 2015), corroborando el nivel de complejidad de los procesos de regulación de la expresión génica. 
La importancia del correcto funcionamiento de este complejo sistema de regulación es notoria. En mamíferos, por ejemplo, el posicionamiento erróneo, la regulación deficiente o la sobre expresión, así como la mutación en las variantes histónicas, son factores que conllevan a la formación y progresión de tumores (Skene \& Henikoff, 2013; Vardabasso et al., 2014). Considerando este punto de vista, las variantes histónicas podrían utilizarse como poderosos biomarcadores epigenéticos en el diagnóstico, pronóstico y desarrollo de nuevas terapias génicas para combatir el cáncer y otras patologías (Stein et al., 2018; Skene \& Henikoff, 2013; Vardabasso et al., 2014; Vijayaraghavalu \& Labhasetwar 2018; Zink \& Hake, 2016).

\section{Variaciones de histonas y regulación de la expresión génica}

Diversos estudios han postulado mecanismos de regulación de la expresión génica basados en las variantes histónicas (Kumar et al., 2012; Picchi et al., 2017; Sabari et al., 2017). En plantas de Arabidopsis thaliana, Kumar \& Wigge (2010) postularon un interesante mecanismo de percepción de temperatura. A temperaturas bajas, nucleosomas con histonas H2A.Z impedían la transcripción de genes como el HSP70, sin embargo, con el aumento de la temperatura la histona provoca que el nucleosoma completo salga de la posición que ocupa, permitiendo la unión de la ARN Pol II y promoviendo de esta manera la transcripción (Figura 3). 


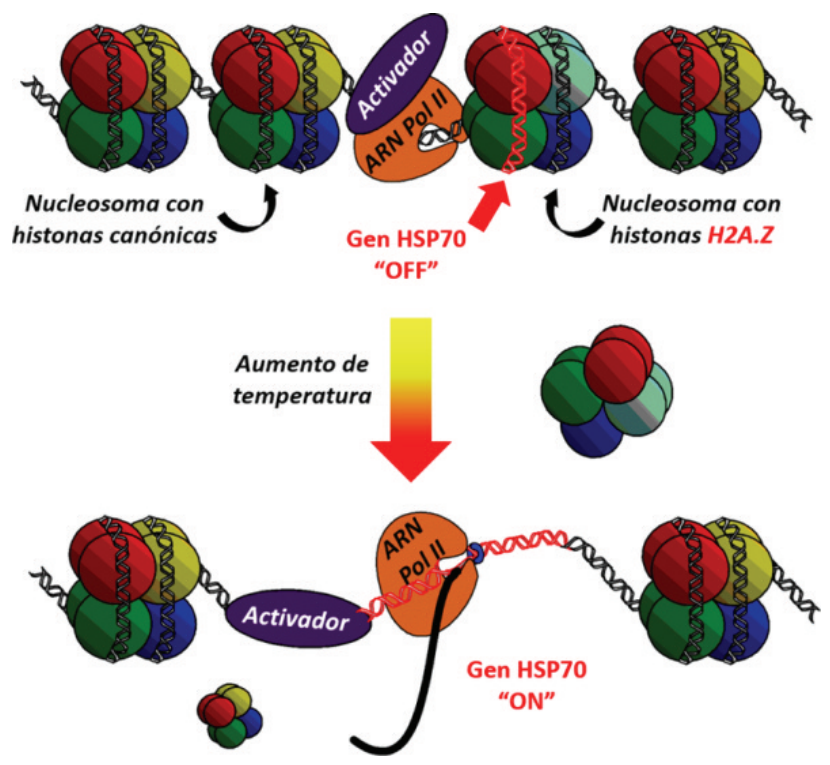

Figura 3. Mecanismo de regulación de la expresión del gen HSP70 en A. thaliana por efecto del aumento de la temperatura, el nucleosoma con las histonas H2A.Z sale, dejando expuesto el gen y permitiendo que este se exprese en respuesta al estímulo. Basado en Kumar \& Wigge (2010).

Por mencionar otro ejemplo, en humanos la variante histónica H2A.X contiene una extensión del extremo carbonilo respecto a $\mathrm{H} 2 \mathrm{~A}$, basado en un motivo de serina-glutamina (SQ) y seguido de un residuo ácido e hidrófobo $[\mathrm{SQ}(\mathrm{E} / \mathrm{D})(\mathrm{I} / \mathrm{L} / \mathrm{Y}]$. Este motivo presenta una fosforilación en su serina S139 que responde al daño sobre el ADN; es a esta modificación post traduccional que se le denomina $\gamma \mathrm{H} 2 \mathrm{~A}$.X o histona guardián del genoma (Vardabasso et al., 2014; Szen- ker et al., 2014; Cheema \& Ausió, 2015; Skene \& Henikoff, 2013). Durante un proceso pueden observarse diversos patrones de reemplazo de histonas con variantes histónicas específicas, al evaluar la abundancia de transcritos de genes que codifican para histonas. Duan et al. (2019) determinó que, durante el desarrollo embrionario de bovinos, pueden involucrarse histonas tipo $\mathrm{H} 1 \mathrm{FOO}$, H3F3A/B, H2AFV/Z, H3F3C y CENPA (Figura 4). 


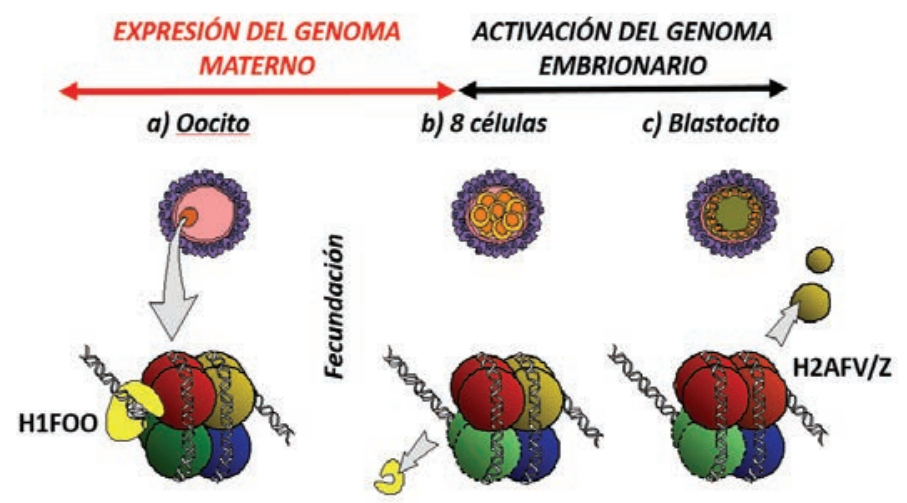

Figura 4. Reemplazos de histonas durante el desarrollo embrionario bovino:

a) el oocito tiene histonas H1FOO dentro de su nucleosoma

b) posterior a la fecundación la histona H1FOO sale facilitando la apertura de la cromatina embrionaria, es probable que también salgan las histonas H3F3A/B del nucleosoma en esta etapa

c) se adicionan las histonas tipo $\mathrm{H} 2 \mathrm{AFV} / \mathrm{Z}$ después de la activación del genoma embrionario, de sus siglas en inglés EGA

(Figura basada en Duan et al. 2019)

En la Tabla 1 se describen algunas variantes histónicas en eucariontes que ilustran mejor la importancia de las

Tabla 1. Principales variantes histónicas respecto a H2A, H2B, H3, H4 y H1. Se detallan algunas características de las variantes. PI se refiere al porcentaje de identidad. mismas en el metabolismo en general.

\section{Referencia}

Variante H2A.X: Contiene una única secuencia C-terminal que está a menudo fosforilada, cuando esto ocurre se conoce a la histona como $\gamma \mathrm{H} 2 \mathrm{~A}$.X. En eucariontes (excepto nematodos) se encuentra en la heterocromatina del telómero, genes codificantes, orígenes de replicación, genes de ARNt y transposones. Repara el ADN, organiza y remodela la cromatina, contribuye a la función neuronal y silenciamiento de cromosomas no pareados en la meiosis. Alrededor de $78 \% \mathrm{PI}$ con $\mathrm{H} 2 \mathrm{~A}$
Talbert \& Henikoff, 2010; Bönisch \& Hake, 2012; Millar, 2013;

Weber \& Henikoff, 2014; Cheema \& Ausió, 2015; Santoro \& Dulac, 2015; Shaytan et al., 2015 
Variante H2A.Z: Posee un dominio ácido en su C-terminal que provoca mayor compactación en el nucleosoma. Se encuentra en todos los eucariontes. Se involucra en la regulación de la expresión génica, formación de la heterocromatina, segregación de cromosomas, reparación del ADN, reprogramación y diferenciación celular, mantenimiento de la estabilidad e integridad del genoma y senescencia celular. Alrededor de $60 \% \mathrm{PI}$ con H2A
Talbert y Henikoff, 2010;

Bönisch y Hake, 2012;

Millar, 2013;

Vardabasso et al; 2013;

Szenker et al., 2014;

Weber y Henikoff, 2014;

Cheema y Ausió, 2015;

Santoro y Dulac, 2015;

Zink y Hake, 2016

Talbert y Henikoff, 2010; Bonisch y Hake, 2012;

Millar, 2013;

Skene y Henikoff, 2013;

Weber y Henikoff, 2014;

Cheema y Ausió, 2015 ción de la transcripción y permite la activación rápida de genes luego de la fertilización. Alrededor de un 48 \% PI con H2A

Variante macroH2A o $\mathbf{m H} 2 \mathrm{~A}$ : En su secuencia con la histona H2A contiene cerca de 200 aminoácidos en su extremo N-terminal que forman un macro dominio de $\sim 30 \mathrm{kDa}$,

Variante macroH2a: Contiene cerca de 200 aminoácidos en su extremo C-terminal que forman un macro dominio de $\sim 30 \mathrm{kDa}$. Se encuentra en vertebrados y unos pocos invertebrados, ubicada en la heterocromatina, eucromatina, telómeros, centrómeros, promotores y genes codificantes, flanqueando el sitio de transcripción. Regula la transcripción (principalmente como represor), inactiva el cromosoma X, participa en la reparación del ADN, contribuye a la función neuronal, suprime muchos tumores e inhibe la reprogramación celular. Alrededor de $60 \% \mathrm{PI}$
Bönisch y Hake, 2012;

Millar, 2013;

Vardabasso et al., 2013;

Szenker et al., 2014;

Volle y Dalal, 2014;

Cheema y Ausió, 2015;

Santoro y Dulac, 2015

\section{HISTONAS H2B}

Variante TH2B o H2B.1: Se encuentra en mamíferos en células del esperma y en telómeros de células somáticas. Se involucra en la espermatogénesis y la reprogramación de la cromatina durante la espermatogénesis, inducción de células pluripotentes. Alrededor de $89 \% \mathrm{PI}$ con H2B.

Cheema y Ausió, 2015; Santoro y Dulac, 2015; Shaytan et al., 2015

Lee et al., 2009;

Szenker et al., 2014;

Cheema y Ausió, 2015;

Shaytan et al., 2015 
Variante H2B.E: Difiere en solo 5 aminoácidos respecto a H2B y Lys5. No se modifica post traduccionalmente. Se encuentra en Mus musculus en genes activos de células neuronales. Se involucra en la modulación y adaptación de neuronas sensoriales olfativas ante Santoro y Dulac, 2012; Santoro y Dulac, 2015 estímulos respiratorios.

\section{HISTONAS H3}

Variante H3.3: Difiere en un rango de 4 a 5 aminoácidos respecto a $\mathrm{H} 3$, gran parte de estas histonas se unen a las histonas H2A.Z (híbridos). Se encuentra en todos los eucariontes en la eucromatina, promotores, elementos regulatorios y en la heterocromatina (telómeros y región pericentromérica). Se involucra en la regulación de la transcripción, plasticidad neuronal, diferenciación celular, formación de la heterocromatina y mantenimiento de la cromatina (memoria epigenética).

Maze et al., 2013;

Vardabasso et al., 2013;

Szenker et al., 2014;

Weber y Henikoff, 2014;

Cheema y Ausió, 2015;

Zink y Hake, 2016

Variante CenH3 o CENP-A en mamíferos: Se encuentra en todos los eucariontes en el centrómero y genes de ARN de transferencia. Regula la integridad estructural y funcional del centrómero, el ensamble de los cinetocoros y, por consiguiente, la segregación cromosómica. Entre 50 a 60 \% Pl.

Vardabasso et al., 2013;

Szenker et al., 2014;

Cheema y Ausió, 2015;

Santoro y Dulac, 2015;

Zink y Hake, 2016

Variante H3.X: Contiene una larga cola en su extremo C-terminal. Se encuentra en los primates en células del cerebro regulando genes activos. Se involucra en la respuesta celular frente a estímulos amWiedemann et al., 2010 bientales y condiciones de estrés.

Variante H3.Y: Se encuentra en primates en ciertos dominios de eucromatina, flanqueando el sitio de inicio de la transcripción. Se involucra en la activación de la transcripción, desarrollo celular y regulación de genes relacionados con la progresión del ciclo celular Wiedemann et al., 2010; Kujirai et al., 2016

\section{HISTONAS H4}

Variantes H4K5ac, H4K8ac, H4K12ac, H4me3, H4K2Ome2, H4me Se involucran en la espermatogénesis en ratones.

Shirakata et al., 2014,

\section{HISTONAS H1}

HIFOO. Variantes H1.1, H1.3, H1.5: Está localizada en oocitos de mamíferos y participa en la diferenciación de células humanas
Hayakawa et al., 2012; Terme et al., 2011 


\section{DISCUSIÓN}

La cromatina está constantemente sujeta a modificaciones que permiten que el DNA se exponga en regiones determinadas y promueva la expresión de genes. Las modificaciones de la cromatina pueden ocurrir a nivel de las histonas, que se presentan de forma canónica o en variantes histónicas (acetilación, metilación, fosforilación etc. de aminoácidos específicos de las histonas). Es interesante mencionar que los efectos acumulados por estas variantes se observan en diferentes etapas del desarrollo celular, debido a que la expresión de genes es regulada exactamente de la forma que la célula necesita. Luco et al., (2011) menciona que las modificaciones a nivel de histonas afectan la fidelidad de la transcripción por splicing alternativo y, por tanto, es factible que la pérdida en la precisión transcripcional se relacione con cambios en las modificaciones de histonas de forma alterada por la edad (Peleg et al., 2016).

Algunos de los trabajos presentados en esta revisión como los de Duan et al., (2019), Zink \& Hake (2016), Weber \& Henikoff (2014) ó Kumar \&
Wigge, (2010) determinaron que, tanto las variantes histónicas como los patrones de regulación derivados de estas variantes, pueden ser desde los más simples hasta los más complejos.

También hay que recalcar que las variantes histónicas, son producto de cambios bioquímicos que determinan su comportamiento. A nivel molecular existen genes que codifican para estas variantes histónicas. Estos genes también tienen patrones de expresión singulares, como mencionaron previamente Cheema \& Ausió, (2015) ó Skene \& Henikoff, (2013). Un aspecto de particular interés se refiere a genes que modifican histonas, es así que Hu et al., (2019), identificaron 16 genes que codifican para proteínas involucradas en la acetilación de histonas (adicionan un grupo acetilo a residuos de lisina en el extremo N-terminal de las histonas del nucleosoma) directamente relacionadas con diferentes tipos de cáncer.

El estudio de las variantes histónicas (genes que las codifican y sus patrones de expresión, genes que causan 
estas variantes o patrones de expresión de genes que se regulan por estas variantes) es un campo sumamente extenso y novedoso. Los efec- tos producidos por estas variantes y las aplicaciones posibles están aún siendo elucidadas.

\section{CONCLUSIÓN}

De todo lo anteriormente expuesto se resalta el profundo impacto que tienen las variantes histónicas sobre los organismos. Estas variantes (como una forma de epigenética) regulan de forma coordinada y fina la expresión de genes en respuesta a factores exógenos. Es por esto que se han consolidado como temas de investigación novedosos y de particular interés.

\section{AGRADECIMIENTOS}

A Lien González, Alejandra Casta- apoyo durante nuestras investigacioñeda y Eileen Vélez por su constante nes. 


\section{LISTA DE REFERENCIAS}

Adalsteinsson, B. T., \& Ferguson-Smith, A. C. (2014). Epigenetic control of the genomelessons from genomic imprinting. Genes, 5(3), 635-655. doi:10.3390/genes 5030635.

Ausió, J. (2015). The shades of gray of the chromatin fiber: recent literature provides new insights into the structure of chromatin. Bioessays, 37(1):46-51. doi: 10.1002/ bies. 201400144

Bönisch, C., \& Hake, S. B. (2012). Histone H2A variants in nucleosomes and chromatin: more or less stable?. Nucleic acids research, 40(21), 10719-10741. doi:10.1093/nar/gks865

Cedar, H., Bergman, Y. (2011). Epigenetics of haematopoietic cell development. Nat Rev Immunol, 11:478-488.

Cheema, M. S., \& Ausió, J. (2015). The Structural Determinants behind the Epigenetic Role of Histone Variants. Genes, 6(3), 685-713. doi:10.3390/genes6030685

Duan, J., Zhu, L., Dong, H., Zheng, X., Jiang, Z., Chen, J., \& Tian, X. C. (2019). Analysis of mRNA abundance for histone variants, histone- and DNA-modifiers in bovine in vivo and in vitro oocytes and embryos. Scientific reports, 9(1), 1217. doi:10.1038/s41598-018-38083-4

Hayakawa, K., Ohgane, J., Tanaka, S., Yagi, S., \& Shiota, K. (2012). Oocyte-specific linker histone $\mathrm{H} 1$ foo is an epigenomic modulator that decondenses chromatin and impairs pluripotency. Epigenetics, 1029-1036. doi:10.4161/epi.21492.

Hergeth, S. P., \& Schneider, R. (2015). The H1 linker histones: multifunctional proteins beyond the nucleosomal core particle. EMBO reports, 16(11), 1439-1453. doi:10.15252/embr.201540749.

Hu, Z., Zhou, J., Jiang, J., Yuan, J., Zhang, Y., Wei, X., ... Zhang, L. (2019). Genomic characterization of genes encoding histone acetylation modulator proteins identifies therapeutic targets for cancer treatment. Nature communications, 10(1), 733. doi:10.1038/s41467-019-08554-x 
Kumar, S. V., Lucyshyn, D., Jaeger, K. E., Alós, E., Alvey, E., Harberd, N. P., \& Wigge, P. A. (2012). Transcription factor PIF4 controls the thermosensory activation of flowering. Nature, 484(7393), 242-245. doi:10.1038/nature10928.

Kumar, S., \& Wigge, P. (2010). H2A.Z-Containing Nucleosomes Mediate the Thermosensory Response in Arabidopsis. Cell, 140:136-147.

Kujirai, T., Horikoshi, N., Sato, K., Maehara, K., Machida, S., Osakabe, A., ... Kurumizaka, H. (2016). Structure and function of human histone H3.Y nucleosome. Nucleic acids research, 44(13), 6127-6141. doi:10.1093/nar/gkw202

Lauria, M., Rossi.,V. (2011) Epigenetic control of gene regulation in plants. Biochim Biophys, 809:369-78.

Lee, J., Park, H. S., Kim, H. H., Yun, Y. J., Lee, D. R., \& Lee, S. (2009). Functional polymorphism in H2BFWT-5'UTR is associated with susceptibility to male infertility. Journal of cellular and molecular medicine, 13(8B), 1942-1951. doi:10.1111/j.1582-4934.2009.00830.x

Luco, R. F., Allo, M., Schor, I. E., Kornblihtt, A. R., \& Misteli, T. (2011). Epigenetics in alternative pre-mRNA splicing. Cell, 144(1), 16-26. doi:10.1016/j.cell.2010.11.056

Luger, K., Mäder, A., Richmond, R., Sargent D., Richmond, T. (1997). Crystal structure of the nucleosome core particle at 2.8 A resolution. Nature, 389(6648):251-60.

Margueron, R., \& Reinberg, D. (2010). Chromatin structure and the inheritance of epigenetic information. Nature reviews. Genetics, 11(4), 285-296. doi:10.1038/nrg2752.

Maze, I., Noh, K. M., \& Allis, C. D. (2013). Histone regulation in the CNS: basic principles of epigenetic plasticity. Neuropsychopharmacology: official publication of the American College of Neuropsychopharmacology, 38(1), 3-22. doi:10.1038/npp.2012.124.

Millar, C. (2013). Organizing the genome with H2A histone variants. Biochem J, 449:567-579. 
Peleg, S., Feller, C., Ladurner, A., \& Imhof, A. (2016). The Metabolic Impact on Histone Acetylation and Transcription in Ageing. Trends Biochem Sci, 41(8):700-711. doi: 10.1016/j.tibs.2016.05.008.

Picchi, G., Zulkievics, V., Krieger, M., Zanchin, N., Goldberg, S., \& de Godoy L. (2017). Post-translational modifications of Trypanosoma cruzi canonical and variant histones. J. Proteome Res, 3;16(3):1167-1179.

Ray-Gallet, D., \& Almouzni G. (2010). Nucleosome dynamics and histone variants. Essays Biochem, 48:75-87

Santoro, S. W., \& Dulac, C. (2015). Histone variants and cellular plasticity. Trends in genetics: TIG, 31(9), 516-527. doi:10.1016/j.tig.2015.07.005.

Santoro, S. W., \& Dulac, C. (2012). The activity-dependent histone variant H2BE modulates the life span of olfactory neurons. eLife, 1, e00070. doi:10.7554/eLife.00070

Sabari, B. R., Zhang, D., Allis, C. D., \& Zhao, Y. (2017). Metabolic regulation of gene expression through histone acylations. Nature reviews. Molecular cell biology, 18(2), 90-101. doi:10.1038/nrm.2016.140

Shaytan, A. K., Landsman, D., \& Panchenko, A. R. (2015). Nucleosome adaptability conferred by sequence and structural variations in histone $\mathrm{H} 2 \mathrm{~A}-\mathrm{H} 2 \mathrm{~B}$ dimers. Current opinion in structural biology, 32, 48-57. doi:10.1016/j.sbi.2015.02.004.

Shirakata, Y., Hiradate, Y., Inoue, H., Sato, E., \& Tanemura, K. (2014). Histone h4 modification during mouse spermatogenesis. The Journal of reproduction and development, 60(5), 383-387. doi:10.1262/jrd.2014-018

Szenker, E., Boyarchuk, E., \& Almouzni, G. (2014). Properties and functions of histone variants. En J. Workman J., S. Abmayr, Fundamentals of Chromatin (págs. 375426.). New York: Springer.

Stein, E. M., Garcia-Manero, G., Rizzieri, D. A., Tibes, R., Berdeja, J. G., Savona, M. R., ... Tallman, M. S. (2018). The DOT1L inhibitor pinometostat reduces H3K79 methylation and has modest clinical activity in adult acute leukemia. Blood, 131(24), 2661-2669. doi:10.1182/blood-2017-12-818948. 
Skene, P., \& Henikoff, S. (2013). Histone variants in pluripotency and disease. Development, 2513-2524. doi:10.1242/dev.091439.

Springer, N., \& Kaeppler, S. (2009) Epigenetics. The Second Genetic Code. En D. Sparks, Advances in Agronomy 100, (págs. 59-80). San Diego: Academic Press.

Tachiwana, H., Kagawa, W., Shiga, T., Osakabe, A., Miya, Y., Saito, K., ... Kurumizaka, H. (2011). Crystal structure of the human centromeric nucleosome containing CENP-A. Nature, 476(7359), 232-235. doi:10.1038/nature10258

Talbert, P., \& Henikoff S. (2010) Histone variants ancient wrap artists of the epigenome. Nat Rev Mol Cell Biol, 11:264-275.

Tammen, S. A., Friso, S., \& Choi, S. W. (2013). Epigenetics: the link between nature and nurture. Molecular aspects of medicine, 34(4), 753-764. doi:10.1016/j.mam. 2012.07.018.

Tarakhovsky, A. (2010) Tools and landscapes of epigenetics. Nat Immunol, 11:565-568.

Terme, J. M., Sesé, B., Millán-Ariño, L., Mayor, R., Izpisúa Belmonte, J. C., Barrero, M. J., \& Jordan, A. (2011). Histone $\mathrm{H} 1$ variants are differentially expressed and incorporated into chromatin during differentiation and reprogramming to pluripotency. The Journal of biological chemistry, 286(41), 35347-35357. doi:10.1074/jbc. M111.281923

Tost J. (2009) DNA Methylation: An Introduction to the Biology and the Disease-Associated Changes of a Promising Biomarker. En C. Tost DNA Methylation Methods and Protocols. (págs. 4-5). New York: Humana Press.

Vijayaraghavalu, S., \& Labhasetwar, V. (2018). Nanogel-mediated delivery of a cocktail of epigenetic drugs plus doxorubicin overcomes drug resistance in breast cancer cells. Drug delivery and translational research, 8(5), 1289-1299. doi:10.1007/ s13346-018-0556-y.

Vardabasso, C., Hasson, D., Ratnakumar, K., Chung, C. Y., Duarte, L. F., \& Bernstein, E. (2014). Histone variants: emerging players in cancer biology. Cellular and molecular life sciences: CMLS, 71(3), 379-404. doi:10.1007/s00018-013-1343. 
Volle, C., \& Dalal, Y. (2014). Histone variants: the tricksters of the chromatin world. Current opinion in genetics \& development, 25, 8-138. doi:10.1016/j.gde.2013. 11.006

Waddington, C. (1942). The epigenotype. Endeavour, 1, 18-20.

Weber, C. M., \& Henikoff, S. (2014). Histone variants: dynamic punctuation in transcription. Genes \& development, 28(7), 672-682. doi:10.1101/gad.238873.114.

Wiedemann, S., Mildner, S., Bönisch, C., Israel, L., Maiser, A., Matheisl S., Straub, T,. Merkl R., Leonhardt H., Kremmer, E., Schermelleh, L., \& Hake, S. (2010). Identification and characterization of two novel primate-specific histone $\mathrm{H} 3$ variants, H3.X and H3.Y. J Cell Biol, 190:777-791.

Zink, L., \& Hake, S. (2016) Histone variants: Nuclear function and disease. Curr Opin Genetics Dev, 37:82-89. 